\title{
Lupin and soya reduce glycaemia acutely in type 2 diabetes
}

\author{
Emma R. Dove ${ }^{1}$, Trevor A. Mori ${ }^{1}$, Gerard T. Chew ${ }^{1}$, Anne E. Barden ${ }^{1}$, Richard J. Woodman ${ }^{2}$, \\ Ian B. Puddey ${ }^{1}$, Sofia Sipsas ${ }^{3}$ and Jonathan M. Hodgson ${ }^{1 *}$ \\ ${ }^{1}$ School of Medicine and Pharmacology, University of Western Australia and the WAIMR Centre for Food and Genomic \\ Medicine, Perth, WA, Australia \\ ${ }^{2}$ Discipline of General Practice, Flinders University, Adelaide, SA, Australia \\ ${ }^{3}$ Department of Agriculture and Food, South Perth, WA, Australia
}

(Received 22 September 2010 - Revised 5 January 2011 - Accepted 11 February 2011 - First published online 10 May 2011)

\section{Abstract}

Addition of fibre or protein to carbohydrate-rich foods can reduce the glycaemic response to those foods. This may assist with glycaemic management in individuals with type 2 diabetes. Lupin is a legume rich in fibre and protein. We assessed the acute effects of lupin- and soya-based beverages on glucose and insulin responses in type 2 diabetic individuals. We hypothesised that the lupin and soya beverages would lower the acute glycaemic response compared with a control beverage containing no protein or fibre, and that lupin would reduce the postprandial glucose more than soya. In a randomised, controlled, cross-over trial, twenty-four diabetic adults (nineteen men and five women) attended three testing sessions, each 1 week apart. At each session, participants consumed a beverage containing $50 \mathrm{~g}$ glucose (control), $50 \mathrm{~g}$ glucose plus lupin kernel flour with $12.5 \mathrm{~g}$ fibre and $22 \mathrm{~g}$ protein (lupin), or $50 \mathrm{~g}$ glucose plus $12.5 \mathrm{~g}$ fibre and $22 \mathrm{~g}$ protein from soya isolates (soya). Serum glucose, insulin and C-peptide were measured periodically for $4 \mathrm{~h}$ following beverage consumption. Compared with the control beverage, the $4 \mathrm{~h}$ post-beverage glucose response was lower $(P<0 \cdot 001)$, and the $4 \mathrm{~h}$ post-beverage insulin and C-peptide responses were higher $(P<0 \cdot 001)$ for lupin and soya. Glucose $(P=0.25)$ and C-peptide $(P=0.07)$ responses did not differ significantly between lupin and soya, but lupin resulted in a lower insulin response compared with soya $(P=0 \cdot 013)$. Adding lupin or soya to a carbohydrate-rich beverage reduces glycaemia acutely in type 2 diabetic individuals. This may have a beneficial role in glycaemic management.

Key words: Lupin: Soya: Diabetes: Glucose: Protein

Both dietary fibre and protein have been demonstrated to reduce postprandial glycaemia ${ }^{(1,2)}$. This suggests that the addition of fibre and protein to high-carbohydrate foods may assist with acute glycaemic control in type 2 diabetes. Lupin flour, derived from lupin endosperm, is a legume product containing $25-30 \%$ fibre and $40-45 \%$ protein, with negligible sugar and starch. Lupin flour has been successfully incorporated into a range of food products. However, its effects on glycaemia, particularly in type 2 diabetes, have not been widely studied.

Among non-diabetic adults, consumption of bread enriched with lupin flour reduced blood glucose levels, with a concomitant increase in postprandial insulin levels, in one study ${ }^{(3)}$ but not in another ${ }^{(4)}$. The incorporation of fibre from lupin into high-carbohydrate foods appears to have only weak effects on glycaemia. In a study of non-diabetic adults, postprandial blood glucose was unaffected and insulin was decreased compared with control $^{(5)}$, while there were no effects on glucose or insulin in a study of adults with noninsulin-dependent diabetes mellitus ${ }^{(6)}$.

There is evidence that particular components of lupin may have anti-hyperglycaemic effects. Conglutin- $\gamma$, a protein contained in lupin seed, exerts an insulin-like action ${ }^{(7)}$ and reduces glycaemia in hyperglycaemic rats in a dose-dependent manner ${ }^{(8)}$. Lupin also contains various phytochemicals and amino acids that have been suggested to assist in the reduction of postprandial glycaemia ${ }^{(3)}$. The unique combination of nutritive components in lupin raises the possibility that its effects on glycaemia may differ from other nutritional sources of protein and fibre. There is some evidence that glycaemia is affected differentially by different sources of protein and fibre ${ }^{(6,9)}$. Soya is a legume, similar to lupin, and is a commonly used food ingredient. Soya-based products have been shown to reduce glycaemia in healthy adults $^{(10)}$, although its effects have not been compared with lupin. 
The aim of the present study was to assess the acute effects of a lupin-based beverage on glucose and insulin responses in type 2 diabetic subjects, and to compare these effects with those of a soya-based beverage matched for macronutrients, primarily fibre and protein. We hypothesised that the lupin and soya beverages would lower the acute glycaemic response compared with the control beverage. Additionally, we hypothesised that lupin, which contains conglutin- $\gamma$, would lower postprandial glycaemia more than soya.

\section{Materials and methods}

\section{Participants}

We recruited individuals with type 2 diabetes, aged 35-65 years, from the general population using newspaper advertisements. The diagnosis of diabetes was confirmed by either a fasting serum glucose $\geq 7 \mathrm{mmol} / 1$, the participant's registration with the National Diabetes Services Scheme (which requires a medical diagnosis of diabetes), or a communication with the participant's general practitioner (with a review of relevant clinical data). Exclusion criteria included type 1 diabetes, duration of diabetes $>10$ years; insulin use; glycated $\mathrm{Hb}$ $>9 \%$; change in body weight $>10 \%$ in the previous 6 months; cigarette use in the previous 6 months; daily ethanol consumption $>30 \mathrm{~g}$ for females or $>40 \mathrm{~g}$ for males; known allergy to lupin, nuts, soya, dairy, wheat or gluten; other major chronic illness; change in regular prescription medications in the previous 3 months. The present study was conducted according to the guidelines laid down in the Declaration of Helsinki, and all procedures involving human subjects were approved by the Royal Perth Hospital Ethics Committee (Perth, WA, Australia). Written informed consent was obtained from all subjects. The trial was registered with the Australian New Zealand Clinical Trials Registry (ACTRN: 12609000375257).

\section{Study design}

In this randomised, controlled, cross-over trial, eligible participants attended three testing sessions, each 7-14d apart. At each study visit, participants consumed a beverage containing glucose (control), glucose plus lupin (lupin) or glucose plus soya (soya). The test beverages were administered in a random order assigned by computer-generated random numbers concealed in opaque envelopes that were opened sequentially by the chief investigator. Participants were not told which beverage they received at each visit. Participants were requested to maintain their usual diet, physical activity and medications for the duration of their involvement in the study. To avoid a second-meal effect ${ }^{(11)}$, participants were asked to consume the same meal on the evening before each visit. Participants were also asked not to consume alcohol or engage in vigorous physical activity for $24 \mathrm{~h}$ before each visit. Anti-hyperglycaemic medications were withheld on the morning of each study visit.

Participants attended each study visit at 08.00 hours following a $12 \mathrm{~h}$ fast. An intravenous cannula was inserted into the antecubital vein through which a single baseline blood sample was drawn after a rest period of $15 \mathrm{~min}$ from cannula insertion. Participants then consumed the test beverage over 5-10 min. Further blood samples were drawn at 15, 30, 45, 60, 90, 120, 180 and $240 \mathrm{~min}$ after beverage consumption. After the final blood sample was collected, the cannula was removed and participants were provided with a meal.

\section{Test beverages}

The three test beverages contained $50 \mathrm{~g}$ glucose (control), $50 \mathrm{~g}$ glucose plus lupin flour (lupin) or $50 \mathrm{~g}$ glucose plus soya protein and fibre isolates (soya). All three beverages were matched for total volume and carbohydrate and fat content, and the lupin and soya beverages were matched for protein and fibre content (Table 1).

The beverages were prepared at the beginning of each test day. Glucose powder (Glucodin; Reckitt Benckiser, West Ryde, NSW, Australia) was dissolved in $50 \mathrm{ml}$ of boiling water and prepared as a lemon-flavoured cordial (made with $0.5 \mathrm{~g}$ citric acid, $0.5 \mathrm{~g}$ tartaric acid and $3.5 \mathrm{ml}$ lemon juice) in order to mask the flavour and improve the palatability of the beverages. This mixture, containing $50 \mathrm{~g}$ of glucose, was used as the base for all three test beverages. Following cooling of the glucose mixture to room temperature, water at room temperature was added to a total volume of $600 \mathrm{ml}$. To make the lupin beverage, $50 \mathrm{~g}$ lupin flour were added to the beverage. Lupin flour was finely milled from the dehulled kernels of Australian sweet lupin (Lupinus angustifolius) sourced from the Department of Agriculture and Food, Western Australia. To make the soya beverage, $22 \mathrm{~g}$ of protein from soya protein isolate and $12.5 \mathrm{~g}$ of fibre from soya fibre isolate were added to the $600 \mathrm{ml}$ glucose and water mixture. Isolates of soya fibre (Fibrim 1020 IP) and protein (Supro XT 219D IP) were provided by Solae Australia (Chatswood, NSW, Australia). Rapeseed oil was added to the soya and control beverages to match the fat content of the lupin beverage. The final macronutrient content and ingredients in the beverages are shown in Table 1. The lupin and soya beverages were homogenised for $30 \mathrm{~s}$ before presentation to the participants in a translucent drink bottle. Immediately after finishing the beverage, each participant added a further $200 \mathrm{ml}$ of water to the drink bottle and drank this to ensure that all the test ingredients were consumed.

Table 1. Ingredients and energy and nutrient composition of the control, lupin and soya test beverages

\begin{tabular}{lccc}
\hline & Control & Lupin & Soya \\
\hline Ingredients & & & \\
$\quad$ Glucose $(\mathrm{g})$ & 50 & 50 & 50 \\
Lupin kernel flour $(\mathrm{g})$ & 0 & 50 & 0 \\
Soya protein isolate $(\mathrm{g})$ & 0 & 0 & 22 \\
$\quad$ Soya fibre isolate $(\mathrm{g})$ & 0 & 0 & 18 \\
$\quad$ Rapeseed oil $(\mathrm{g})$ & 3.5 & 0 & 2.6 \\
Energy/nutrient values & & & \\
$\quad$ Energy (kJ) & 961 & 1460 & 1460 \\
Carbohydrate (g) & 50 & 50 & 50 \\
Protein (g) & 0 & 22 & 22 \\
Fibre (g) & 0 & 12.5 & 12.5 \\
Fat (g) & 3.5 & 3.5 & 3.5 \\
\hline
\end{tabular}




\section{Biochemical analyses}

Venous blood was collected into serum tubes and centrifuged at $1500 \mathrm{~g}$ for $10 \mathrm{~min}$ at $4^{\circ} \mathrm{C}$, and aliquots were stored at $-80^{\circ} \mathrm{C}$ until analysed. Glucose was measured by a hexokinase method using a fully automated analyser (Hitachi 917; F. Hoffmann-La Roche Ltd, Basel, Switzerland), with an interassay $\mathrm{CV}$ of $<3 \%$. Insulin was measured by ELISA (Boehringer Mannheim, Mannheim, Germany), with an inter-assay CV of $<2 \%$. C-peptide was measured using a solid-phase, two-site chemiluminescent immunometric assay (Siemens Medical Solutions Diagnostics, Los Angeles, CA, USA) with an interassay $\mathrm{CV}$ of $<5 \%$. All samples from each individual were analysed in the same assay to minimise variability.

\section{Statistics}

Statistical analyses were performed using SPSS 15.0 (SPSS, Inc., Chicago, IL, USA) and STATA 10 (StataCorp, College Station, TX, USA). The primary endpoints of interest were the $4 \mathrm{~h}$ post-beverage serum glucose, insulin and C-peptide responses. Differences between baseline values and between peak values for each treatment were assessed using ANOVA with Tukey's adjustment for multiple comparisons. A random-effects linear model was fitted to observed data for each variable (glucose, insulin and C-peptide). Each model consisted of a random intercept and slope to account for individual participant variability due to within-participant correlations. The models also contained fixed-effects for treatment group, time as a categorical variable with nine categories $(0,15,30,45,60,90,120,180$ and $240 \mathrm{~min})$, treatment order and treatment period. Treatment order and period were removed from the final models. Mean post-beverage differences between treatments were assessed with a mixed-effects model that included a random intercept, main effects for treatment and main effects for time.

\section{Results}

\section{Participant characteristics}

Of the twenty-nine eligible participants randomised to treatment, twenty-four (nineteen men and five women) completed the study (Fig. 1); three participants withdrew for personal reasons; one because of illness; one because of difficulty obtaining blood samples. The characteristics of the study participants are shown in Table 2 . Of the twenty-four participants, eight $(33 \%)$ were on diet treatment alone for their diabetes, fourteen (58\%) were treated with metformin, one (4\%) was taking gliclazide and one (4\%) was prescribed both metformin and gliclazide. Other concomitant therapies included anti-hypertensive (79\%) and cholesterol-lowering (58\%) medications.

\section{Serum glucose, insulin and C-peptide responses}

At baseline, the mean fasting glucose (control, 7·4 (SD 1·1) mmol/1; lupin, $7 \cdot 4(\mathrm{SD} 1.2) \mathrm{mmol} / \mathrm{l}$; soya, 7.5 (SD 1.2) $\mathrm{mmol} / \mathrm{l})$, insulin (control, 14 (SD 7) mU/l; lupin, 13 (SD 7) mU/l; soya, 14 (SD 7) $\mathrm{mU} / \mathrm{l}$ ) and C-peptide (control, $1 \cdot 1$ (SD 0.4) mmol/l; lupin, $1.0(\mathrm{sD} 0.4) \mathrm{mmol} / \mathrm{l}$; soya, $1.0(\mathrm{sD} 0.4) \mathrm{mmol} / \mathrm{l})$ concentrations were not different according to the test beverage $(P>0.5)$. The glucose, insulin and C-peptide concentrations measured over $4 \mathrm{~h}$ post-beverage consumption are presented in Fig. 2. The glucose response was lower for lupin and soya $(P<0 \cdot 001)$ compared with control but was not significantly different between lupin and soya $(P=0 \cdot 25$; Fig. $2(\mathrm{a}))$. The insulin response was higher for lupin and soya compared with control $(P<0 \cdot 001)$, and lower for lupin compared with soya $(P=0 \cdot 013$; Fig. 2(b)). The C-peptide response was higher for lupin and soya compared with control $(P<0 \cdot 001)$, but the difference between lupin and soya did not reach significance $(P=0 \cdot 07$; Fig. 2(c)). Peak glucose concentrations were attained $45 \mathrm{~min}$ after ingestion of each beverage (control, 13.0 (SD 1.7) $\mathrm{mmol} / \mathrm{l}$; lupin, 11.6

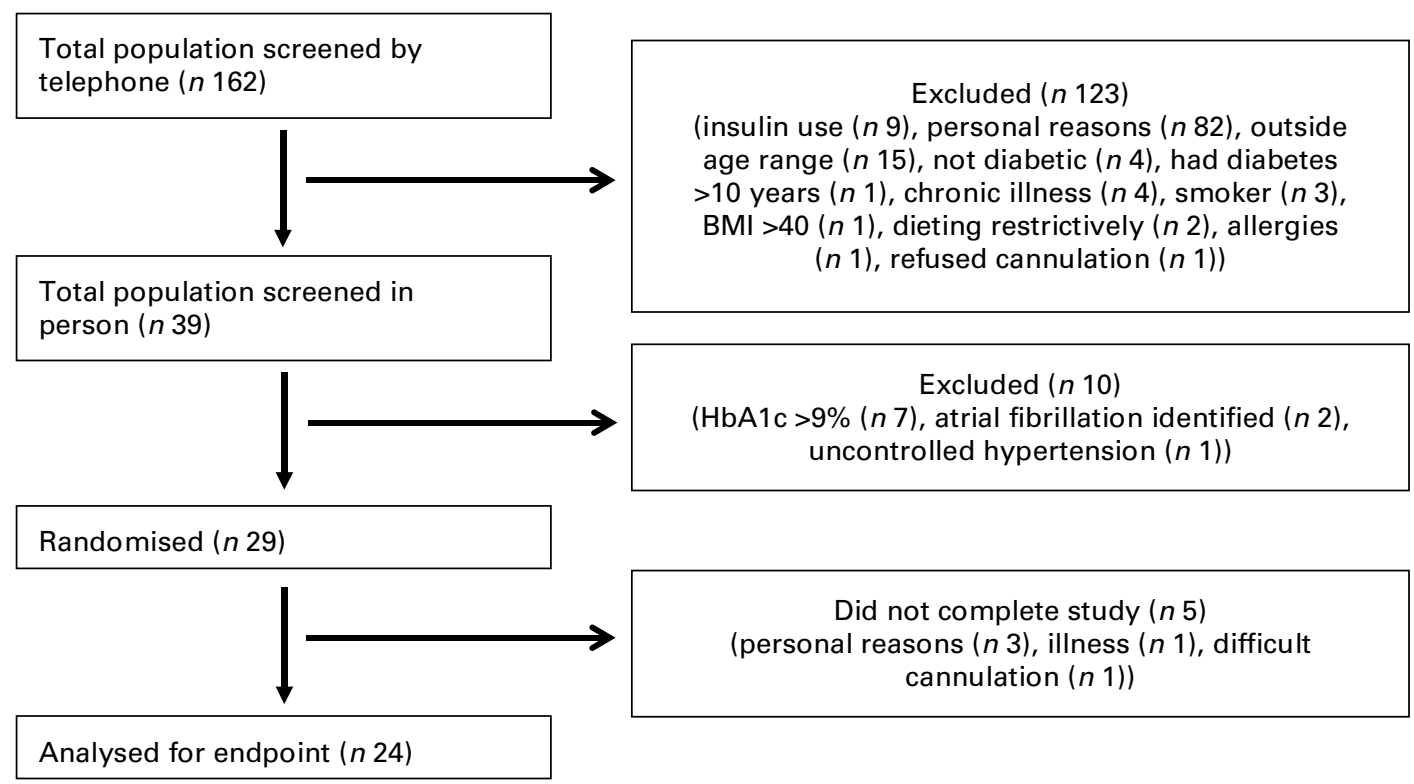

Fig. 1. Trial profile showing the number of participants at each stage of study recruitment and completion. 
Table 2. Participant characteristics

(Mean values, standard deviations and ranges, $n$ 24)

\begin{tabular}{|c|c|c|c|}
\hline Variables & Mean & SD & Range \\
\hline Age (years) & $57 \cdot 0$ & $6 \cdot 6$ & $44-66$ \\
\hline Body weight (kg) & 94.9 & $16 \cdot 5$ & $69 \cdot 45-125 \cdot 75$ \\
\hline BMI $\left(\mathrm{kg} / \mathrm{m}^{2}\right)$ & $30 \cdot 9$ & $4 \cdot 8$ & $22 \cdot 9-40 \cdot 9$ \\
\hline Systolic blood pressure (mmHg) & 130 & 14 & $108-159$ \\
\hline Diastolic blood pressure $(\mathrm{mmHg})$ & 75 & 8 & $59-92$ \\
\hline Glycated $\mathrm{Hb}(\%)$ & $6 \cdot 7$ & 0.5 & $5 \cdot 4-7 \cdot 8$ \\
\hline Fasting glucose $(\mathrm{mmol} / \mathrm{l})$ & $7 \cdot 1$ & 0.9 & $5.5-8.9$ \\
\hline Total cholesterol (mmol/l) & $4 \cdot 1$ & 0.7 & $2 \cdot 8-5 \cdot 5$ \\
\hline $\mathrm{TAG}(\mathrm{mmol} / \mathrm{l})$ & 1.6 & 0.8 & $0.5-3.5$ \\
\hline LDL-cholesterol (mmol/l) & $2 \cdot 3$ & 0.7 & $1 \cdot 2-3 \cdot 9$ \\
\hline HDL-cholesterol (mmol/l) & $1 \cdot 1$ & 0.3 & $0.7-1 \cdot 8$ \\
\hline Duration of diabetes (months) & 44 & 37 & $4-120$ \\
\hline
\end{tabular}

(SD 1.7$) \mathrm{mmol} / \mathrm{l}$; soya, $11 \cdot 1$ (sD $2 \cdot 0) \mathrm{mmol} / \mathrm{l}$ ) and were lower for lupin and soya $(P<0.001)$ compared with control but not significantly different between lupin and soya $(P=0 \cdot 13)$.

\section{Discussion}

Consistent with our first hypothesis, the acute glycaemic response to a carbohydrate-rich beverage in individuals with type 2 diabetes was reduced with the addition of lupin and soya. Our second hypothesis was not supported - we found that both lupin and soya reduced glycaemia to a similar degree. Both lupin and soya increased insulin levels postbeverage compared with control, but lupin had a lesser effect compared with soya.

The present results are consistent with those reported by Hall et $a l^{(3)}$ in non-diabetic individuals. The reduction in glycaemia resulting from lupin and soya may be attributed to several factors, including an increase in viscosity, an increase in gastrointestinal solids, a delay in gastric emptying time, the presence of hypoglycaemic phytochemicals and the increased protein and/or fibre content in the legumebased beverages. As Hall et $a l^{(3)}$ observed, further research is needed to elucidate the role of each of these factors in reducing glycaemia ${ }^{(3)}$.

It seems likely that the protein content of the lupin and soya beverages contributed significantly to their glucose-reducing effects. We postulate this based on the substantial increase in insulin and C-peptide in response to both lupin and soya that we observed. Dietary protein enhances insulin secretion in both healthy and diabetic individuals ${ }^{(1,12)}$. Supporting this, studies using isolated fibre from lupin ${ }^{(5)}$ and oat gum ${ }^{(13)}$ have demonstrated a decrease in insulin levels compared with a control meal. There are several mechanisms by which protein may attenuate postprandial hyperglycaemia; these include slowing of gastric emptying and intestinal delivery and absorption of glucose ${ }^{(1)}$, and stimulation of insulin secretion via (i) an effect on incretin hormones ${ }^{(1)}$ or (ii) an effect of amino acids on pancreatic $\beta$-cells ${ }^{(14)}$. We did not assess these specific mechanisms in the present study.

The present results suggest that there is no difference in the extent to which lupin and soya have a glucose-reducing effect, and this is probably due to similarities between lupin and soya with respect to properties of their protein and fibre. Few studies have directly compared the acute effects of protein from different sources on glycaemia. In one study, whey protein decreased glucose and increased insulin levels more than meat protein in those with type 2 diabetes ${ }^{(15)}$. Gannon et al. ${ }^{(12)}$ studied the effects of protein from a variety of sources, including beef, turkey, gelatin, egg-white, cottage cheese, fish and soya, on glucose and insulin responses in type 2 diabetic individuals and concluded that, though there was variation in the magnitude of the effects, all resulted in raised insulin and decreased blood glucose levels (except egg-white). The reason that some studies do show differences, whereas
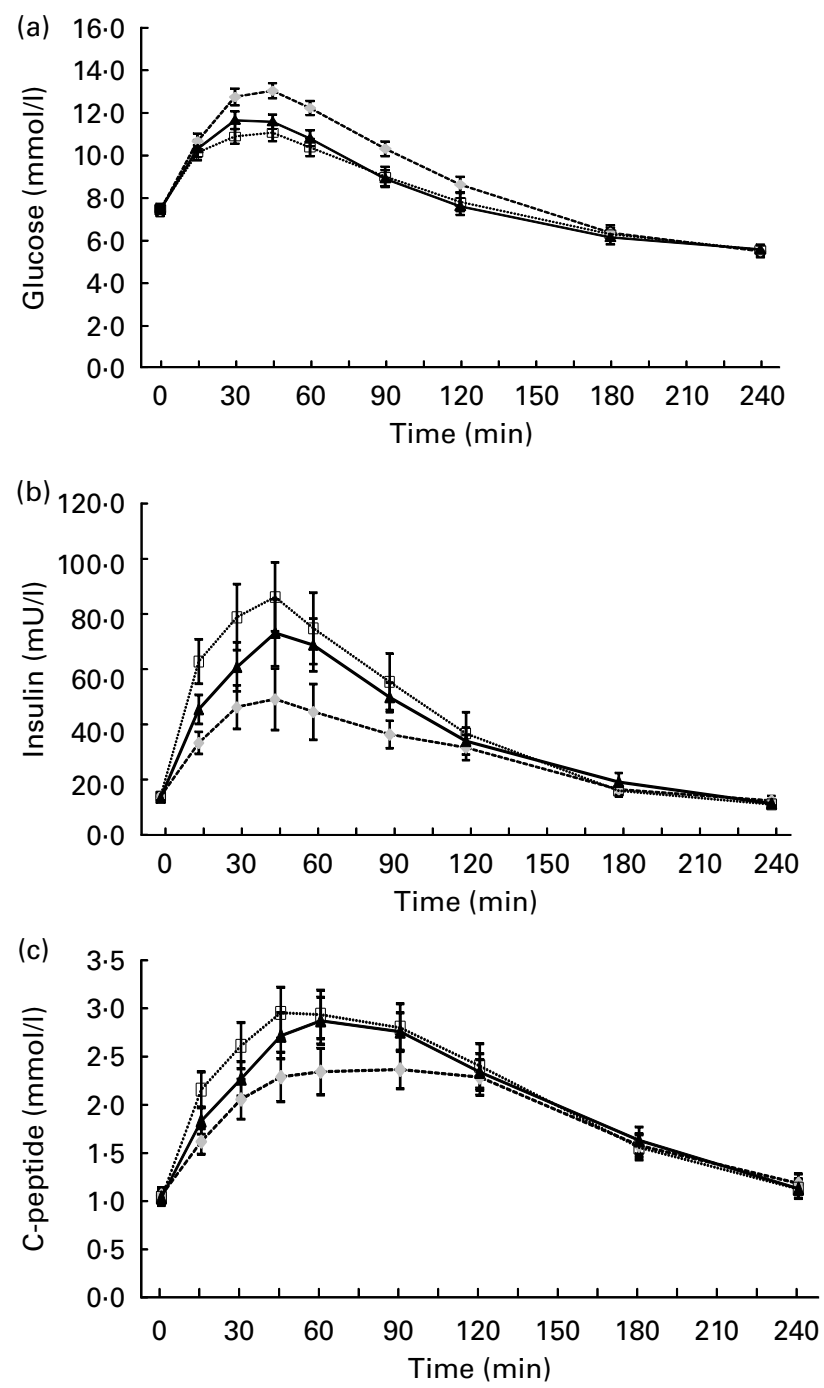

Fig. 2. (a) Serum glucose, (b) insulin and (c) C-peptide concentrations in $4 \mathrm{~h}$ after consumption of the control (-----), lupin (- - ) and soya $(\cdots . . . . . . .$.$) beverages ( n$ 24). Values are means, with their standard errors represented by vertical bars (with treatment effects analysed using mixed models). Mean values of post-beverage glucose levels over $4 \mathrm{~h}$ were significantly different for lupin and soya compared with control $(P<0.001)$, but not significantly different between lupin and soya $(P=0.25)$. Mean values of post-beverage insulin levels were significantly different for lupin and soya compared with control $(P<0.001)$, and significantly different for lupin compared with soya $(P=0.013)$. Mean values of post-beverage $C$-peptide levels were significantly different for lupin and soya compared with control $(P<0.001)$, but not significantly different between lupin and soya $(P=0.07)$. 
others do not, may relate to the ability to detect very small differences. The present results are generally consistent with previous findings and indicate little, if any, difference between lupin and soya on the glucose response.

The dietary fibre content of lupin and soya may also have contributed to the reduction in glycaemia compared with control. Many studies have shown that soluble fibre improves glycaemia in type 2 diabetic individuals, probably by slowing gastric emptying and decreasing glucose absorption ${ }^{(2,16)}$. However, lupin ${ }^{(17)}$ and soya ${ }^{(18)}$ contain predominantly insoluble fibre, and although insoluble fibre has been shown to reduce glycaemia in some studies ${ }^{(19,20)}$, only small effects on glycaemia have been shown in studies of healthy and diabetic individuals consuming lupin kernel fibre ${ }^{(5,6)}$ and soya fibre ${ }^{(21,22)}$. Therefore, the glycaemic effects of the legumebased beverages are likely to be more attributable to their increased protein rather than increased fibre content.

Control of hyperglycaemia following food and beverage consumption is an important treatment goal in diabetes management. Postprandial glycaemia may contribute more than fasting glycaemia to overall glycaemic control, especially at lower glycated $\mathrm{Hb}$ levels ${ }^{(23-25)}$. There is now a large body of evidence, including observational prospective cohort studies, randomised controlled trials, and mechanistic studies in animal models, which supports the consumption of lowglycaemic index foods and diets for the prevention of type 2 diabetes and $\mathrm{CVD}^{(26)}$. Postprandial hyperglycaemia, by increasing oxidative stress, endothelial dysfunction and advanced glycation $^{(26)}$, may also be an independent risk factor for $\mathrm{CVD}^{(27)}$. There is some evidence that therapies targeting postprandial glycaemia may reduce cardiovascular events $^{(28,29)}$. Therefore, dietary intake of legumes such as lupin and soya that reduce postprandial glycaemia may assist in the glycaemic management and prevention of diabetic complications and CVD. This may be most effective in early diabetes when $\beta$-cell function and endogenous insulin secretory capacity are less impaired. The subjects in the present study had diabetes of relatively short-to-medium duration, and the glycaemic effects of legumes may be more limited in patients with more advanced diabetes.

In the present study, we found that although lupin and soya resulted in the same glycaemic response to a fixed glucose load, lupin resulted in a significantly lower insulin response.

The importance and reliability of this difference in insulin secretion (between lupin and soya) for the long-term management of blood glucose in type 2 diabetic individuals and risk of CVD is not clear. However, it may have implications for the risk of type 2 diabetes and CVD. Hyperinsulinaemia is associated with increased risk of type 2 diabetes ${ }^{(30)}$ and $\mathrm{CVD}^{(31)}$. In addition, there is evidence that acute hyperinsulinaemia can cause endothelial dysfunction ${ }^{(32)}$, sympathetic hyperactivity $^{(33)}$ and reduced $\mathrm{Na}$ excretion $^{(34)}$. In the longer term, these effects may contribute to endothelial dysfunction, hypertension and elevated risk of CVD.

It is unclear why the post-beverage insulin levels in the present study were lower with lupin than with soya. While it is possible that soya protein is more insulinotropic than lupin protein, the results may also be related to differences in the presentation of the soya and lupin proteins in the present study. Lupin protein was presented as part of lupin flour, whereas soya protein was presented as an isolate. It is possible that soya protein isolate may have been digested more quickly or had greater bioavailability than the lupin protein in the milled lupin flour. Whether a component of lupin flour, such as conglutin- $\gamma^{(8)}$, might have also contributed to reducing blood glucose levels through insulin-mimetic effects ${ }^{(7)}$ merits further investigation. There have been no previous studies that have compared the effects of lupin and soya protein isolates on glycaemia and insulin levels.

It is not known whether the beneficial glycaemic effects of legumes are sustained in the long term. Population studies are consistent in demonstrating benefits of low-glycaemic index foods and low-glycaemic index diets for glycaemic control and insulin sensitivity in type 2 diabetes, and insulin sensitivity and risk of developing type 2 diabetes in healthy subjects ${ }^{(30-36)}$. The evidence that short-term regular consumption of legumes ${ }^{(37,38)}$ improves insulin sensitivity and glycaemic control is mixed, and may depend on the type of legume and the health status of the population studied. A recently published longer-term intervention study of postmenopausal Chinese women with pre-diabetes and untreated early diabetes found no effect of soya protein on glycaemic control and insulin sensitivity over 6 months ${ }^{(39)}$. The evidence for the benefit of high-protein diets on insulin sensitivity and glycaemic control in type 2 diabetes is mixed. Some studies have reported improved insulin sensitivity, and others have reported poorer insulin sensitivity and diabetic control ${ }^{(40-44)}$.

A limitation of the present study is that lupin and soya were provided as beverages rather than solid foods. Although lupin flour is more often consumed in solid foods, it could be used to supplement or fortify beverages in the future. Soya protein, in particular, and fibre are already commonly used in 'soya milks'. In the present study, it was necessary to use beverages in order to investigate the effects of lupin on the glucose and insulin responses to a fixed dose of carbohydrate. We have previously conducted an acute trial that examined the effects of a lupin-enriched meal of solid food (bread), which was energy matched with a control meal, on post-meal glucose and insulin responses ${ }^{(4)}$. We observed a significant reduction in the glucose response and a decrease in the insulin response at a trend level $(P=0 \cdot 06)$. However, given the large reduction in the provision of glycaemic carbohydrate, because lupin flour partially replaced wheat flour in bread, the impact of lupin flour itself, rather than the reduction in carbohydrate, on glucose and insulin responses was unclear. To understand the effects of lupin flour on glucose and insulin responses, it is necessary to match the dose of carbohydrate. The present findings provide evidence that lupin flour itself is responsible for the effects on both glucose and insulin independent of the glycaemic load.

We conclude that adding lupin or soya to an oral carbohydrate load reduces glycaemia acutely. Lupin has similar glycaemic effects to soya but with less insulin stimulation. The results of the present study add to our understanding of the acute effects of lupin and soya on glucose and insulin responses. It would be beneficial for other studies to examine 
the effects of conglutin- $\gamma$ on glycaemia in human subjects. Investigation of the longer-term effects of regular consumption of a lupin-enriched diet on glycaemic control and insulin sensitivity is warranted in order to ascertain whether lupin may benefit glycaemic management in type 2 diabetic individuals.

\section{Acknowledgements}

None of the authors has any conflict of interest to declare. The present study was supported by the Western Australian Government, Department of Industry and Resources. E. R. D. contributed to the study concept and design, acquisition, statistical analysis and interpretation of the data, and drafting and revision of the manuscript. T. A. M. and J. M. H. contributed to the study concept and design, acquisition, statistical analysis and interpretation of the data, drafting and revision of the manuscript, and obtaining funding. G. T. C. contributed to the study concept and design, medical management of the study participants, interpretation of the data, and drafting and revision of the manuscript. A. E. B. contributed to the study concept and design, analysis and interpretation of the data and revision of the manuscript. R. J. W. contributed to the analysis and interpretation of the data, and revision of the manuscript. I. B. P. and S. S. contributed to the study concept and design, revision of the manuscript and obtaining funding.

\section{References}

1. Karamanlis A, Chaikomin R, Doran S, et al. (2007) Effects of protein on glycemic and incretin responses and gastric emptying after oral glucose in healthy subjects. Am J Clin Nutr 86, 1364-1368.

2. Pick ME, Hawrysh ZJ, Gee MI, et al. (1996) Oat bran concentrate bread products improve long-term control of diabetes: a pilot study. J Am Diet Assoc 96, 1254-1261.

3. Hall RS, Thomas SJ, Johnson SK, et al. (2005) Australian sweet lupin flour addition reduces the glycaemic index of a white bread breakfast without affecting palatability in healthy human volunteers. Asia Pac J Clin Nutr 14, 91-97.

4. Lee YP, Mori TA, Sipsas S, et al. (2006) Lupin-enriched bread increases satiety and reduces energy intake acutely. Am J Clin Nutr 84, 975-980.

5. Johnson SK, McQuillan PL, Sin JH, et al. (2003) Sensory acceptability of white bread with added Australian sweet lupin (Lupinus angustifolius) kernel fibre and its glycaemic and insulinaemic responses when eaten as a breakfast. $J$ Sci Food Agric 83, 1366-1372.

6. Feldman N, Norenberg C, Voet H, et al. (1995) Enrichment of an Israeli ethnic food with fibres and their effects on the glycaemic and insulinaemic responses in subjects with non-insulin-dependent diabetes mellitus. $\mathrm{Br} J$ Nutr $\mathbf{7 4}$, 681-688.

7. Terruzzi I, Senesi P, Magni C, et al. (2010) Insulin-mimetic action of conglutin- $\gamma$, a lupin seed protein, in mouse myoblasts. Nutr Metab Cardiovasc Dis 21, 197-205.

8. Magni C, Sessa F, Accardo E, et al. (2004) Conglutin gamma, a lupin seed protein, binds insulin in vitro and reduces plasma glucose levels of hyperglycemic rats. J Nutr Biochem 15, 646-650.
9. Jenkins DJ, Wolever TM, Wong GS, et al. (1984) Glycemic responses to foods: possible differences between insulindependent and noninsulin-dependent diabetics. Am J Clin Nutr 40, 971-981.

10. Blair R, Henley EC \& Tabor A (2006) Soy foods have low glycemic and insulin response indices in normal weight subjects. Nutr J 5, 35.

11. Wolever TM, Jenkins DJ, Ocana AM, et al. (1988) Secondmeal effect: low-glycemic-index foods eaten at dinner improve subsequent breakfast glycemic response. $\mathrm{Am} \mathrm{J}$ Clin Nutr 48, 1041-1047.

12. Gannon MC, Nuttall FQ, Neil BJ, et al. (1988) The insulin and glucose responses to meals of glucose plus various proteins in type II diabetic subjects. Metabolism 37, 1081-1088.

13. Braaten JT, Wood PJ, Scott FW, et al. (1991) Oat gum lowers glucose and insulin after an oral glucose load. Am J Clin Nutr, [see comment] 53, 1425-1430.

14. Nuttall FQ \& Gannon MC (1991) Plasma glucose and insulin response to macronutrients in nondiabetic and NIDDM subjects. Diabetes Care 14, 824-838.

15. Frid AH, Nilsson M, Holst JJ, et al. (2005) Effect of whey on blood glucose and insulin responses to composite breakfast and lunch meals in type 2 diabetic subjects. Am J Clin Nutr 82, 69-75.

16. Brennan CS (2005) Dietary fibre, glycaemic response, and diabetes. Mol Nutr Food Res 49, 560-570.

17. Evans AJ \& Cheung PCK (1993) The carbohydrate composition of cotyledons and hulls of cultivars of Lupinus angustifolius from Western Australia. J Sci Food Agric 61, 189-194.

18. Burkhalter TM, Merchen NR, Bauer LL, et al. (2001) The ratio of insoluble to soluble fiber components in soybean hulls affects ileal and total-tract nutrient digestibilities and fecal characteristics of dogs. J Nutr 131, 1978-1985.

19. Hamedani A, Akhavan T, Samra RA, et al. (2009) Reduced energy intake at breakfast is not compensated for at lunch if a high-insoluble-fiber cereal replaces a low-fiber cereal. Am J Clin Nutr 89, 1343-1349.

20. Samra RA \& Anderson GH (2007) Insoluble cereal fiber reduces appetite and short-term food intake and glycemic response to food consumed $75 \mathrm{~min}$ later by healthy men. Am J Clin Nutr 86, 972-979.

21. Tsai AC, Mott EL, Owen GM, et al. (1983) Effects of soy polysaccharide on gastrointestinal functions, nutrient balance, steroid excretions, glucose tolerance, serum lipids, and other parameters in humans. Am J Clin Nutr 38, 504-511.

22. Tsai AC, Vinik AI, Lasichak A, et al. (1987) Effects of soy polysaccharide on postprandial plasma glucose, insulin, glucagon, pancreatic polypeptide, somatostatin, and triglyceride in obese diabetic patients. Am J Clin Nutr 45, 596-601.

23. Fonseca V (2003) Clinical significance of targeting postprandial and fasting hyperglycemia in managing type 2 diabetes mellitus. Curr Med Res Opin 19, 635-641.

24. Ratner RE (2001) Controlling postprandial hyperglycemia. Am J Cardiol 88, 26H-31H.

25. Woerle HJ, Neumann C, Zschau S, et al. (2007) Impact of fasting and postprandial glycemia on overall glycemic control in type 2 diabetes importance of postprandial glycemia to achieve target HbA1c levels. Diabetes Res Clin Pract 77, 280-285.

26. Potenza MA, Gagliardi S, Nacci C, et al. (2009) Endothelial dysfunction in diabetes: from mechanisms to therapeutic targets. Curr Med Chem 16, 94-112.

27. Cavalot F, Petrelli A, Traversa M, et al. (2006) Postprandial blood glucose is a stronger predictor of cardiovascular events than fasting blood glucose in type 2 diabetes mellitus, 
particularly in women: lessons from the San Luigi Gonzaga Diabetes Study. J Clin Endocrinol Metab 91, 813-819.

28. Chiasson J-L, Josse RG, Gomis R, et al. (2003) Acarbose treatment and the risk of cardiovascular disease and hypertension in patients with impaired glucose tolerance: the STOP-NIDDM trial. JAMA 290, 486-494.

29. Hanefeld M, Cagatay M, Petrowitsch T, et al. (2004) Acarbose reduces the risk for myocardial infarction in type 2 diabetic patients: meta-analysis of seven long-term studies. Eur Heart J 25, 10-16.

30. Brand-Miller J, Hayne S, Petocz P, et al. (2003) Low-glycemic index diets in the management of diabetes: a meta-analysis of randomized controlled trials. Diabetes Care $\mathbf{2 6}$, 2261-2267.

31. Dickinson S \& Brand-Miller J (2005) Glycemic index, postprandial glycemia and cardiovascular disease. Curr Opin Lipidol 16, 69-75.

32. Hodge AM, English DR, O'Dea K, et al. (2004) Glycemic index and dietary fibre and the risk of type 2 diabetes. Diabetes Care 27, 2701-2706.

33. Jarvi AE, Karlstrom BE, Granfeldt YE, et al. (1999) Improved glycemic control and lipid profile and normalized fibrinolytic activity on a low-glycemic index diet in type 2 diabetic patients. Diabetes Care 22, 10-18.

34. Salmeron J, Ascherio A, Rimm EB, et al. (1997) Dietary fiber, glycemic load, and risk of NIDDM in men. Diabetes Care 20, $545-550$.

35. Du H, van der ADL, van Bakel MME, et al. (2008) Glycemic index and glycemic load in relation to food and nutrient intake and metabolic risk factors in a Dutch population. Am J Clin Nutr 87, 655-661.

36. Schulze MB, Liu S, Rimm EB, et al. (2004) Glycemic index, glycemic load, and dietary fiber intake and incidence of type 2 diabetes in younger and middle-aged women. $A m \mathrm{~J}$ Clin Nutr 80, 348-356.
37. Jang Y, Lee JH, Kim OY, et al. (2001) Consumption of whole grain and legume powder reduces insulin demand, lipid peroxidation, and plasma homocysteine concentrations in patients with coronary artery disease: randomized controlled clinical trial. Arterioscler Thromb Vasc Biol 21, 2065-2071.

38. Nestel P, Cehun M \& Chronopoulos A (2004) Effects of longterm consumption and single meals of chickpeas on plasma glucose, insulin, and triacylglycerol concentrations. Am J Clin Nutr 79, 390-395.

39. Liu Z-M, Chen Y-M, Ho SC, et al. (2010) Effects of soy protein and isoflavones on glycemic control and insulin sensitivity: a 6-mo double-blind, randomized, placebocontrolled trial in postmenopausal Chinese women with prediabetes or untreated early diabetes. Am J Clin Nutr 91. 1394-1401.

40. Boden G, Sargrad K, Homko C, et al. (2005) Effect of a low-carbohydrate diet on appetite, blood glucose levels, and insulin resistance in obese patients with type 2 diabetes. Ann Intern Med 142, 403-411. (Summary for patients in Ann Intern Med 2005; 142, I44; PMID: 15767614).

41. Farnsworth E, Luscombe ND, Noakes M, et al. (2003) Effect of a high-protein, energy-restricted diet on body composition, glycemic control, and lipid concentrations in overweight and obese hyperinsulinemic men and women. Am J Clin Nutr 78, 31-39.

42. Linn T, Geyer R, Prassek S, et al. (1996) Effect of dietary protein intake on insulin secretion and glucose metabolism in insulin-dependent diabetes mellitus. J Clin Endocrinol Metab 81, 3938-3943.

43. Rossetti L, Rothman DL, DeFronzo RA, et al. (1989) Effect of dietary protein on in vivo insulin action and liver glycogen repletion. Am J Physiol 257, E212-E219.

44. Samaha FF, Iqbal N, Seshadri P, et al. (2003) A lowcarbohydrate as compared with a low-fat diet in severe obesity. N Engl J Med 348, 2074-2081. 